\title{
Anti-4-1BB monoclonal antibodies attenuate concanavalin A-induced immune-mediated liver injury in mice
}

\author{
GUANGTAO XIA $^{1 *}$, SENSEN WU $^{2 *}$ and YUANCHAO ZHANG ${ }^{1}$ \\ ${ }^{1}$ Department of Rheumatology, Provincial Hospital Affiliated to Shandong University, Jinan, Shandong 250021; \\ ${ }^{2}$ Department of General Surgery, Qilu Hospital of Shandong University, Jinan, Shandong 250012, P.R. China
}

Received April 24, 2015; Accepted February 22, 2016

DOI: $10.3892 /$ etm.2016.3503

\begin{abstract}
Effective therapies for the treatment of immune-mediated liver disease are currently lacking. As a member of the tumor necrosis factor receptor superfamily, 4-1BB has a key role in T-cell activation and has been implicated in the development of autoimmune disorders. The purpose of the present study was to evaluate the potential therapeutic or preventive function of an anti-4-1BB monoclonal antibody (mAb) in a mouse model of concanavalin (Con) A-induced immune-mediated liver injury. A mouse model of immune-mediated liver injury was established by tail vein injection of Con A (20 mg/kg). 4-1BB mAb $(100 \mu \mathrm{g})$, with or without methylprednisolone (MEP; $3 \mathrm{mg} / \mathrm{kg}$ ), was intraperitoneally injected into the tail vein $2 \mathrm{~h}$ prior to or $2 \mathrm{~h}$ following Con A injection. Con A induced marked hepatocyte necrosis, significantly reduced $\mathrm{CD} 4^{+} / \mathrm{CD} 25^{+} \mathrm{T}$-cell levels, and increased the serum levels of aspartate transaminase (AST) and alanine transaminase (ALT), in addition to the percentage of $4-1 \mathrm{BB}^{+} \mathrm{T}$-cells, compared with the control (all $\mathrm{P}<0.05$ ). The administration of 4-1BB $\mathrm{mAb}$ prior to or following Con A injection was able to attenuate Con A-induced liver tissue damage and significantly reduce serum AST and ALT levels $(\mathrm{P}<0.05)$. A combination of MEP and 4-1BB mAb further reduced serum AST and ALT levels, compared with either treatment alone. In addition, administration of 4-1BB mAb and MEP alone or in combination significantly increased $\mathrm{CD}^{+} / \mathrm{CD} 25^{+}$ T-cell levels, compared with the control $(\mathrm{P}<0.05)$. These results suggested that $4-1 \mathrm{BB} \mathrm{mAb}$ was able to attenuate liver injury and preserve liver function in a mouse model of Con A-induced immune-mediated liver injury by promoting the expansion of $\mathrm{CD}^{+} / \mathrm{CD} 25^{+}$T-cells. Furthermore, a combination of $4-1 \mathrm{BB}$ $\mathrm{mAb}$ with MEP was associated with greater beneficial effects
\end{abstract}

Correspondence to: Dr Guangtao Xia, Department of Rheumatology, Provincial Hospital Affiliated to Shandong University, 324 Jingwu Road, Jinan, Shandong 250021, P.R. China E-mail: xiaguangtao@126.com

*Contributed equally

Key words: anti-4-1BB monoclonal antibody, $\mathrm{CD} 4^{+} / \mathrm{CD} 25^{+} \mathrm{T}-$ cell, concanavalin A, immune-mediated liver injury, methylprednisolone than either treatment alone. The clinical significance of 4-1BB $\mathrm{mAb}$ in immune-mediated liver disease remains to be elucidated in future studies.

\section{Introduction}

Immune-mediated liver disease is caused by abnormal immune responses in the liver. Numerous cell types are attacked by the immune system, leading to liver damage and other organ disorders $(1,2)$. The three major immune-mediated liver diseases include primary biliary cirrhosis, primary sclerosing cholangitis and autoimmune hepatitis, and these are associated with differing autoimmune pathogenic mechanisms (3-5). The estimated prevalence of the overlap syndrome (presentation of clinical characteristics of a second auto-immune liver disease in patients with an existing auto-immune liver disease) of immune-mediated liver disease is $5-20 \%$ (6). Although the exact etiology remains unclear, evidence has suggested that impairment of apoptotic cell debri clearance may contribute to the development of immune-mediated liver disease (3). Immunosuppressive therapies, including corticosteroids, have been effective in relieving the symptoms of autoimmune hepatitis, however, therapeutic progress remains limited (1,7).

4-1BB is an inducible T-cell surface receptor that belongs to the tumor necrosis factor receptor (TNFR) superfamily. 4-1BB is typically expressed at very low levels on naive T-cells; however, its expression is induced upon T-cell activation, such that it is expressed at relatively high levels on activated T-cells (8-10). The interaction of $4-1 \mathrm{BB}$ with its ligand (4-1BBL) regulates $\mathrm{T}$-cell-mediated immune responses by providing CD 28-independent co-stimulation for T-cell activation $(8,10)$. Previous studies on transgenic mice demonstrated that 4-1BBL-deficient transgenic mice were less responsive to the influenza virus, and that 4-1BB knockout mice had reduced T-cell activity. These findings further supported a role for 4-1BB in T-cell-mediated immune responses (10-13).

4-1BB and 4-1BBL have previously been associated with the development of autoimmune disease. The expression levels of 4-1BBL in the duct epithelial cells of salivary glands were previously demonstrated to be markedly elevated in a mouse model of Sjörgren's syndrome and were associated with the severity of sialadenitis (14). In addition, 4-1BBL has been indicated to be essential for the development of autoimmune encephalomyelitis in a mouse model of multiple sclerosis (15). 
In another study, the serum levels of the soluble forms of 4-1BB and 4-1BBL were significantly higher in patients with rheumatoid arthritis, as compared with those in healthy controls, and were correlated with disease severity (16). Furthermore, patients with multiple sclerosis exhibited increased serum levels of soluble 4-1BBL, as compared with healthy controls (17).

The role of 4-1BB and 4-1BBL in immune-mediated liver disease remains unclear. Therefore, the present study aimed to analyze the expression levels of 4-1BB in the T-cells of a mouse model of concanavalin A (Con A)-induced immune-mediated liver injury. In addition, the effects of an anti-4-1BB monoclonal antibody (4-1BB mAb) on Con A-induced liver injury were investigated.

\section{Materials and methods}

Reagents. Con A was obtained from Sigma-Aldrich (St. Louis, MO, USA). Fluorescence-conjugated anti-mouse CD3 (1:100; cat. no. 100204), anti-mouse CD4 (1:100; cat. no. 130308, anti-mouse CD25 (cat. no. 101908) and 4-1BB (LEAF purified anti-mouse CD137; cat. no. 106107) monoclonal antibodies were purchased from BioLegend, Inc. (San Diego, CA, USA) and diluted 1:100. Methylprednisolone (MEP) was purchased from GE Healthcare Life Sciences (Uppsala, Sweden).

Establishment of a mouse model of Con A-induced immune-mediated liver injury. A total of 60 male Kunming mice (age, 6-7-weeks; weight, 20-30 g) were purchased from the Animal Center of Shandong Province (Jinan, China). The mice were maintained in a clean room under a 12-h dark:light cycle at $22-26^{\circ} \mathrm{C}$ and $40-70 \%$ humidity, at the Animal Care Center of Shandong University, with ad libitum access to food and water. All experimental procedures were approved by the ethics committee at Shandong University (Jinan, China).

In order to establish a mouse model of immune-mediated liver injury, the mice were injected with $0.3 \mathrm{ml}$ Con A solution $(20 \mathrm{mg} / \mathrm{kg})$ in phosphate-buffered saline (PBS) into the tail vein. The control mice were injected with $0.3 \mathrm{ml}$ of PBS only. The mice were randomly divided into eight groups, as follows ( $n=10 /$ group): i) The control group, with PBS injection; ii) the Con $\mathrm{A}$ group, Con $\mathrm{A}$ injection; iii) the Con $\mathrm{A}+4-1 \mathrm{BB}$ $\mathrm{mAb}$ group, $4-1 \mathrm{BB} \mathrm{mAb}(100 \mu \mathrm{g})$ was injected into the tail vein at $2 \mathrm{~h}$ post-Con A injection; iv) the Con A + MEP group, mice were intraperitoneally injected with $\operatorname{MEP}(3 \mathrm{mg} / \mathrm{kg})$ at $2 \mathrm{~h}$ post-Con A injection; v) the Con $\mathrm{A}+4-1 \mathrm{BB} \mathrm{mAb}+\mathrm{MEP}$ group, mice were injected with $4-1 \mathrm{BB} \mathrm{mAb}(100 \mu \mathrm{g})$ and $\operatorname{MEP}(3 \mathrm{mg} / \mathrm{kg}$ ) at $2 \mathrm{~h}$ post-Con A injection; vi) the Con $\mathrm{A}+$ preventive $4-1 \mathrm{BB}$ mAb group, $4-1 \mathrm{BB} \mathrm{mAb}(100 \mu \mathrm{g})$ was injected into the tail vein $2 \mathrm{~h}$ prior to Con A injection; vii) the Con $\mathrm{A}+$ control IgG $(100 \mu \mathrm{g})$; and viii) the Con $\mathrm{A}+$ preventive $\operatorname{IgG}(100 \mu \mathrm{g})$. All mice were closely monitored following injection.

Liver function assessment. Following anesthetization by abdominal injection with $2 \%$ pentobarbital solution (Sigma-Aldrich), blood was collected from the heart of mice at $8 \mathrm{~h}$ post-Con A injection. A $50 \mu \mathrm{l}$ aliquot of the blood sample was analyzed using a AU5400 Chemistry Automated Analyzer (Olympus Corporation) to assess the liver function by determining the aspartate transaminase (AST) and alanine transaminase (ALT) levels.

Hematoxylin and eosin (H\&E) staining of liver tissue. The mice were sacrificed by cervical dislocation $8 \mathrm{~h}$ following Con A injection. The liver was dissected, fixed in $4 \%$ formaldehyde for $24 \mathrm{~h}$ and embedded in paraffin (both Sigma-Aldrich). Subsequently, the liver tissue was sectioned into $0.5 \mathrm{~mm}^{3}$ sections using a rotary microtome (Leica Microsystems $\mathrm{GmbH}$, Wetzlar, Germany). Tissue sections were deparaffinized with xylene, followed by sequential washing with anhydrous ethanol, 95\% ethanol, 85\% ethanol and finally, $75 \%$ ethanol. Sections were then washed with water for 4 minutes prior to staining with H\&E (Sigma-Aldrich). Images were captured using a BH2 microscope (Olympus Corporation, Tokyo, Japan) at magnification, x20.

Flow cytometry. In order to prevent coagulation, $50 \mu \mathrm{l}$ ethylenediaminetetraacetic acid (BD Biosciences, Franklin Lakes, NJ, USA) was added to each aliquot of mouse blood, after which, the blood samples were diluted with PBS and incubated with fluorescein isothiocyanate (FITC-conjugated CD3 $(1.25 \mu \mathrm{l})$, phycoerythrin (PE)-conjugated CD4 (1.2 $\mu \mathrm{l})$, FITC-CD25 $(0.5 \mu \mathrm{l})$ or PE-4-1BB $(1 \mu \mathrm{l})$ antibodies on ice for $20 \mathrm{~min}$. Subsequently, the blood samples were incubated with $500 \mu$ l OptiLyse C Hemolysin (Beckman Coulter Inc., Brea, $\mathrm{CA}, \mathrm{USA}$ ) at $37^{\circ} \mathrm{C}$ for $10 \mathrm{~min}$ to lyse and remove erythrocytes, followed by washing with PBS and centrifugation for $5 \mathrm{~min}$ at $430 \mathrm{x}$ g. The cell pellet was resuspended in PBS, mixed and analyzed on a FACScan flow cytometer (BD Biosciences). Data were analyzed using the Epics XL software (version 3.0; Beckman Coulter, Inc.).

Statistical analysis. Data are presented as the mean \pm standard deviation. Statistical analyses were conducted using SPSS software, version 12.0 (SPSS, Inc., Chicago, IL, USA). Intergroup comparisons were conducted using Student's t-test, whereas multigroup comparisons were performed using analysis of variance followed by Dunnett's test. $\mathrm{P}<0.05$ was considered to indicate a statistically significant difference.

\section{Results}

Con A injection induces liver damage in mice. Compared with the control group, the mice that were injected with Con A appeared less active and had a poor appetite. A histopathological examination detected a large number of necrotic hepatocytes in the liver tissue from the Con A group, and these necrotic hepatocytes were smaller, than normal hepatocytes, containing condensed chromatin and exhibiting reticular degeneration and steatosis. In addition, the liver tissue from the Con A group exhibited marked lymphocyte and neutrophil infiltration, in particular within the hepatic portal area. Furthermore, severe erythrocyte sedimentation was observed in the hepatic sinusoid (Fig. 1A and B). The Con A-injected mice exhibited significantly increased serum levels of ALT and AST, compared with the control mice ( $\mathrm{P}<0.01$; Fig. $1 \mathrm{C})$; thus suggesting that the liver function was impaired following Con A injection. In addition, the percentage of 4-1BB-positive T-cells was significantly increased in the Con A-injected mice 

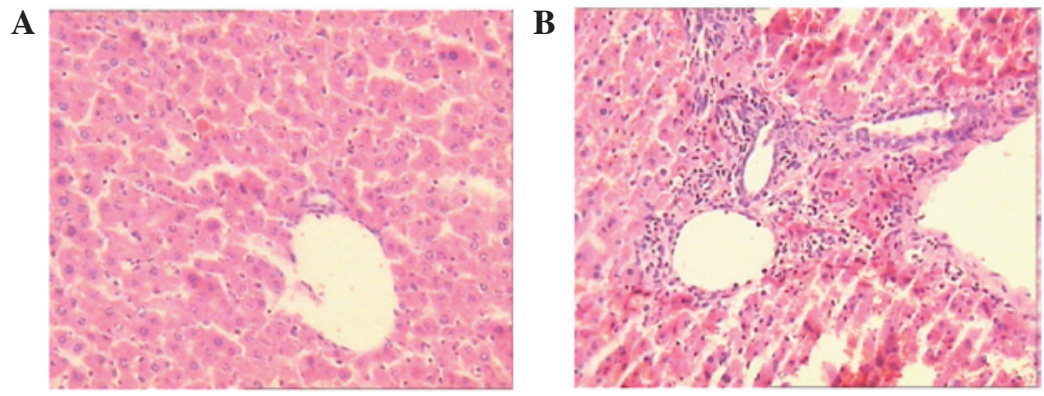

C
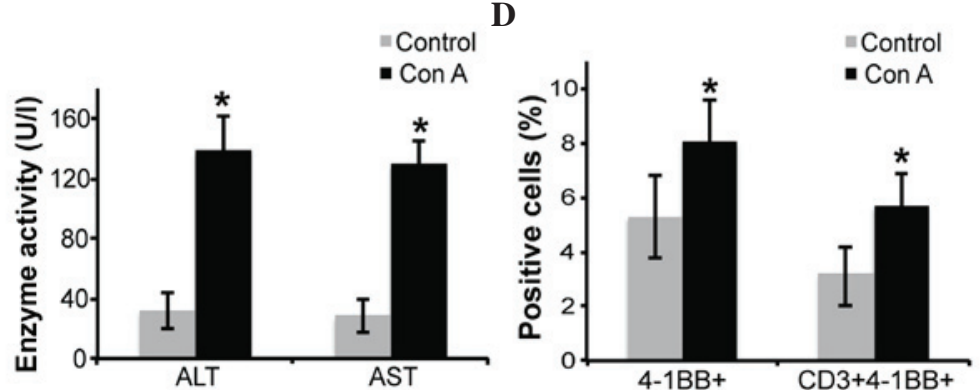

Figure 1. Establishment of the mouse model of Con A-induced immune-mediated liver injury. Representative images of H\&E-stained (A) healthy liver tissue and (B) liver tissue from mice injected with Con A. Mice were sacrificed at $8 \mathrm{~h}$ following Con A injection, after which liver tissue was harvested, fixed and sectioned. Images of H\&E-stained sections were obtained using an Olympus BH2 microscope (magnification, x20). (C) Levels of ALT and AST were significantly increased following Con A injection. Blood samples were collected $8 \mathrm{~h}$ following Con A injection and the ALT and AST levels were measured. (D) Proportion of $\mathrm{CD}^{+} 4-1 \mathrm{BB}^{+} \mathrm{T}$-cells was significantly increased following Con A injection. Blood samples were incubated with CD3-fluorescein isothiocyanate and 4-1BB-phycoerythrin antibodies and analyzed by flow cytometry. Data are presented as the mean \pm standard deviation ( $\mathrm{n}=10)$. ${ }^{*}<0.05$ vs. control. Con A, concanavalin A; H\&E, hematoxylin and eosin; ALT, alanine transaminase; AST, aspartate transaminase; CD3, cluster of differentiation 3.

compared with the control mice ( $\mathrm{P}=0.0018$; Fig. 1D). These results suggest that Con $\mathrm{A}$ injection may cause liver damage in mice and stimulate 4-1BB expression in T-cells.

4-1BB mAb exerts beneficial effects on mice with Con A-induced liver damage. Compared with the control mice, the mice injected with $4-1 \mathrm{BB} \mathrm{mAb}$ at $2 \mathrm{~h}$ post-Con A injection became increasingly active and exhibited an improved appetite at 3-4 h post-injection. H\&E staining detected a marked reduction in hepatocyte necrosis and decreased lymphocyte and neutrophil infiltration into the hepatic portal area in mice treated with 4-1BB, compared with the control group mice (Fig. 2A). Furthermore, the serum levels of ALT and AST were significantly reduced by $4-1 \mathrm{BB} \mathrm{mAb}$ injection post-ConA-induced $(\mathrm{P}<0.01$; Fig. $2 \mathrm{~B})$, which indicated that treatment with 4-1BB mAb was able to preserve liver function in Con A-injected mice. Consistent with these results, injection with $4-1 \mathrm{BB} \mathrm{mAb}$ at $2 \mathrm{~h}$ prior to the induction of liver injury by Con A markedly attenuated Con A-induced liver damage. In addition, preventive treatment of the mice with 4-1BB mAb maintained physical activity, reduced liver tissue damage (Fig. 2A) and preserved liver function in the mice $(\mathrm{P}<0.05$; Fig. 2B) compared with the preventive control IgG.

MEP has been widely used to treat immune-mediated liver disease in clinical practice (5). Therefore, the present study analyzed whether a combination treatment with MEP and 4-1BB mAb would synergistically act to reduce Con A-induced liver damage in mice. Compared with the control, MEP treatment alone improved the physical activity of the mice and reduced liver tissue damage (Fig. 2A) to a similar extent as 4-1BB mAb treatment alone; however, it reduced the serum levels of ALT and AST to a greater extent than 4-1BB mAb treatment alone (Fig. 2C). The effects of combined MEP and 4-1BB mAb on the physical activity of the mice and liver tissue injury (Fig. 2A) appeared similar to those observed for either treatment alone; however, the serum levels of ALT and AST were further reduced following the combined treatment $(\mathrm{P}<0.01$; Fig. $2 \mathrm{C})$. These results suggest that a treatment with MEP combined with 4-1BB mAb may preserve liver function in mice with Con A-induced liver injury.

The proportion of $C D 4^{+} / C D 25^{+} T$-cells increases following $4-1 B B$ mAb treatment. The proportion of $\mathrm{CD}^{+} / \mathrm{CD} 25^{+}$ T-cells was significantly reduced in the Con A-injected mice, compared with the control group mice $(\mathrm{P}<0.05$; Fig. $3 \mathrm{~A})$. Treatment with 4-1BB mAb following Con $\mathrm{A}$ injection and preventive treatment with 4-1BB mAb prior to Con A injection markedly increased the proportion of $\mathrm{CD} 4^{+} / \mathrm{CD} 25^{+}$ T-cells compared with the Con $\mathrm{A}+$ control $\operatorname{IgG}$ group $(\mathrm{P}=0.030$; Fig. 3A). In addition, MEP alone significantly increased the proportion of $\mathrm{CD}^{+} / \mathrm{CD} 25^{+}$T-cells $(\mathrm{P}<0.01$; Fig. 3B), which was further increased by combined treatment of MEP and $4-1 \mathrm{BB} m \mathrm{mAb}$ ( $\mathrm{P}<0.01$ vs. the control; Fig. 3B).

\section{Discussion}

The present study demonstrated that 4-1BB expression was increased on the surface of T-cells following Con A-induced liver injury in mice. This is consistent with previous studies, in which 4-1BB and 4-1BBL were demonstrated to be upregulated in human autoimmune diseases, including rheumatoid 
A
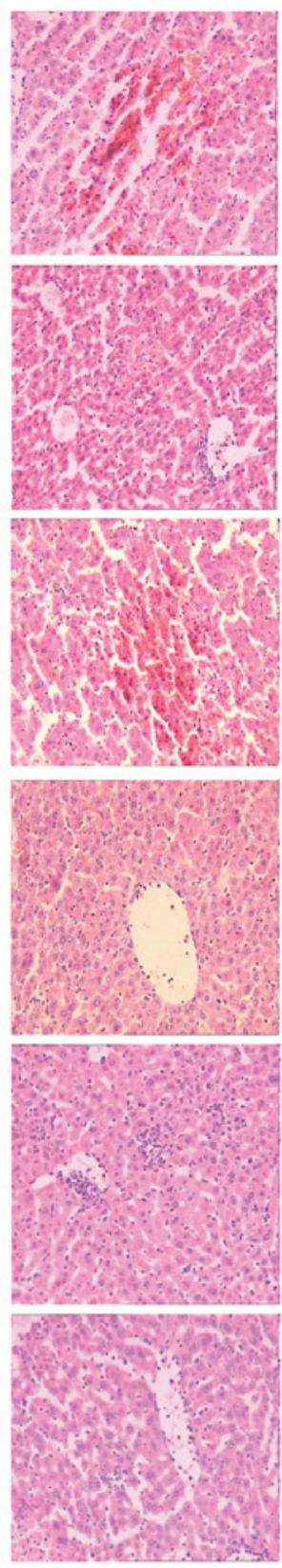

B

Con $\mathrm{A}+$

Control

Con $\mathrm{A}+$

4-1BB mAb

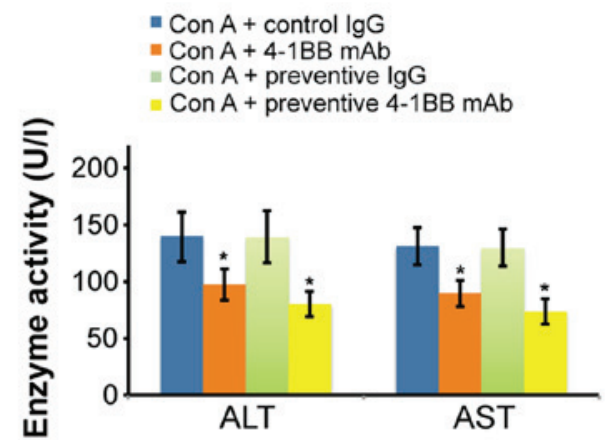

Con $\mathrm{A}+$

Preventive

control

Con $\mathrm{A}+$

C

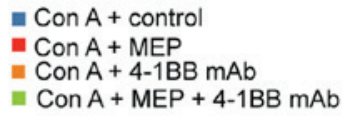

Preventive

4-1BB mAb

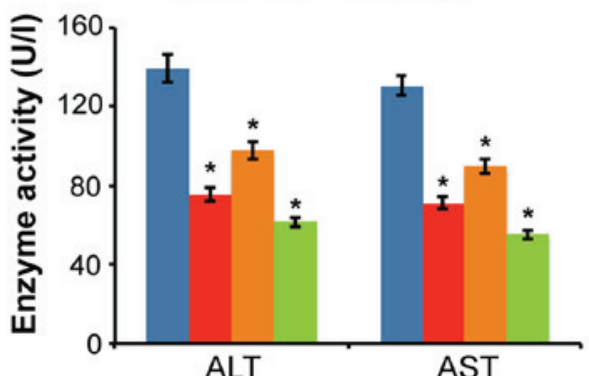

Con $\mathrm{A}+$

$\mathrm{MEP}+$

4-1BB mAb

Figure 2. 4-1BB mAb exerted beneficial effects on mice with Con A-induced liver injury. (A) representative images of H\&E-stained liver tissue from mice treated with the various treatments. (B) Administration of 4-1BB mAb $2 \mathrm{~h}$ after or $2 \mathrm{~h}$ before Con A injection significantly reduced the serum levels of ALT and AST. (C) 4-1BB combined with MEP further reduced the ALT and AST levels. Data are presented as the mean \pm standard deviation. ${ }^{*} \mathrm{P}<0.05$ vs. the Con A + control IgG or Con A + preventive (4-!BB administered 2 h prior to injection with Con A) IgG groups. Con A, concanavalin A; IgG, immunoglobulin G; H\&E, hematoxylin \& eosin; ALT, alanine transaminase; AST, aspartate transaminase; mAb, monoclonal antibody; MEP, methylprednisolone.

arthritis and multiple sclerosis $(16,17)$. Therefore, 4-1BB may have a role in the development of immune-mediated liver disease. The 4-1BB mAb has previously been investigated in animal models of various autoimmune disorders; Haga et al (18) investigated the role of 4-1BB in a rat model of autoimmune myocarditis and reported that inhibition of 4-1BB pathways by intraperitoneal injection with $4-1 \mathrm{BB}$ mAb was able to attenuate the development of disease. In addition, the mRNA expression levels of proinflammatory cytokines in the heart tissue, including interleukin and TNF- $\alpha$, were decreased following 4-1BB mAb treatment (18). In another study, the 4-1BB mAb inhibited the development of a interphotoreceptor retinoid-binding protein-induced autoimmune uveoretinitis by

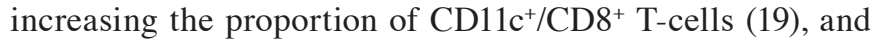
intraperitoneal injection with agonistic 4-1BB mAb markedly reduced the development and severity of experimental autoimmune encephalomyelitis in rats (20). Furthermore, the 4-1BB $\mathrm{mAb}$ markedly reduced mercury-induced autoimmunity in mice (21). In the present study, inhibition of the 4-1BB pathway by intravenous injection with 4-1BB mAb significantly reduced liver tissue damage and preserved liver function in mice with Con A-induced immune-mediated liver injury.

The molecular mechanisms underlying the beneficial effects of the 4-1BB mAb in various animal models of autoimmune disorders remain unclear. Haga et al (18) reported that the $4-1 \mathrm{BB} \mathrm{mAb}$ reduced heart tissue damage and preserved 
A

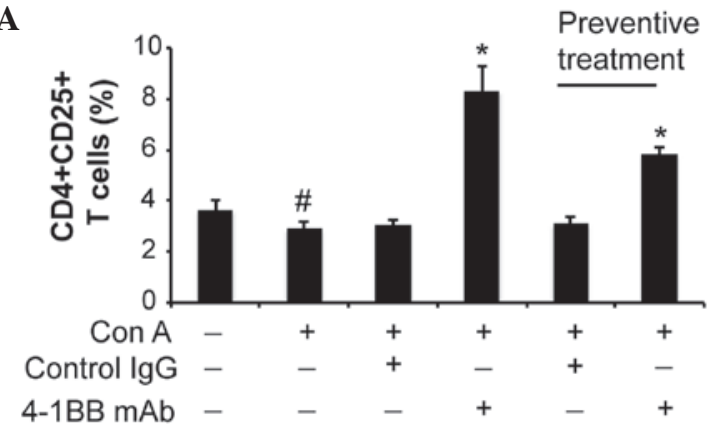

B

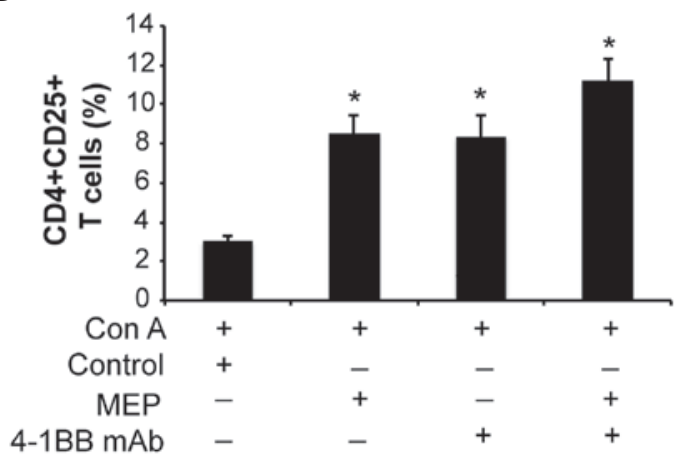

Figure 3. Proportion of $\mathrm{CD} 4^{+} / \mathrm{CD} 25^{+} \mathrm{T}$-cells was significantly increased following treatment with $4-1 \mathrm{BB} \mathrm{mAb}$ and MEP. (A) The proportion of $\mathrm{CD} 4{ }^{+} 1 / \mathrm{CD} 25^{+} \mathrm{T}$-cells was increased following 4-1BB mAb treatment. 4-1BB $\mathrm{mAb}$ was injected into the mouse tail vein at either $2 \mathrm{~h}$ prior to or $2 \mathrm{~h}$ following Con A injection. Data are presented as the mean \pm standard deviation ${ }^{\text {" }} \mathrm{P}<0.01$ vs. the Con $\mathrm{A}+$ control IgG group; ${ }^{~} \mathrm{P}<0.05$ vs. the control group. (B) The combination of MEP and 4-1BB mAb treatment further increased the $\mathrm{CD}^{+} / \mathrm{CD} 25^{+} \mathrm{T}$-cell levels. Mice were intraperitoneally injected with MEP $(3 \mathrm{mg} / \mathrm{kg})$ at $2 \mathrm{~h}$ post-Con A injection. Blood samples were collected $8 \mathrm{~h}$ after Con A injection and incubated with CD4-phycoerythrin and CD25-fluorescein isothiocyanate antibodies and then analyzed by flow cytometry. Data are presented as the mean \pm standard deviation $(n=10)$. ${ }^{*} \mathrm{P}<0.05$ vs. the control group. $\mathrm{CD}$, cluster of differentiation; Con $\mathrm{A}$, concanavalin $\mathrm{A} ; \mathrm{mAb}$, monoclonal antibody; MEP, methylprednisolone.

heart function in a rat model of autoimmune myocarditis by suppressing the activity of the signaling molecules c-Jun $\mathrm{N}$-terminal kinase, p38 and the inhibitor of NF- $\mathrm{B}$. Conversely, Choi et al (19) reported that the inhibitory effects of the 4-1BB $\mathrm{mAb}$ on the development of autoimmune uveoretinitis was not associated with the inhibition of 4-1BB signaling, but with $4-1 \mathrm{BB}$ mAb-mediated expansion of $\mathrm{CD} 11 \mathrm{c}^{+} / \mathrm{CD}^{+}$ T-cells. The present study demonstrated that Con A injection significantly reduced the proportion of $\mathrm{CD} 4^{+} / \mathrm{CD} 25^{+} \mathrm{T}$-cells, and that this was significantly attenuated following treatment with $4-1 \mathrm{BB} \mathrm{mAb}$. A reduction in the number of $\mathrm{CD}^{+} / \mathrm{CD} 25^{+}$ T-cells has been associated with various autoimmune disorders. For example, in a previous study patients with chronic autoimmune urticaria exhibited significantly reduced levels of $\mathrm{CD}^{+} / \mathrm{CD} 25^{+} \mathrm{T}$-cells compared with healthy controls (22), and the absolute count of $\mathrm{CD} 4^{+} / \mathrm{CD} 25^{+} \mathrm{T}$-cells in patients with active systemic lupus erythematosus was markedly lower compared with healthy controls in another study (23). Therefore, Con A-mediated reduction of $\mathrm{CD} 4{ }^{+} / \mathrm{CD} 25^{+} \mathrm{T}$-cells may have contributed to the development of immune-mediated liver injury in the mice, and the protective effects of 4-1BB
mAb may have been due to the increase in $\mathrm{CD} 4^{+} / \mathrm{CD} 25^{+} \mathrm{T}$-cell levels.

The disruption of the 4-1BB/4-1BBL pathway has previously been associated with adverse effects in animal models of autoimmune disorders. Sytwu et al (24) demonstrated that transgenic, non-obese diabetic mice overexpressing membrane-bound agonistic single-chain anti-4-1BB variable fragment in pancreatic $\beta$-cells developed more severe diabetes compared with their non-transgenic littermates. In particular, this was associated with earlier-onset, faster diabetic processes and a higher mortality. In the present study, the short-term effects of 4-1BB mAb treatment in a mouse model of Con A-induced immune-mediated liver injury appeared promising; however, the long-term effects of 4-1BB mAb on liver function remain unclear. Therefore, future studies are required to verify the results of the present study.

In conclusion, the present study demonstrated that the 4-1BB mAb was able to reduce liver tissue damage and preserve liver function in a mouse model of Con A-induced immune-mediated liver injury by increasing the proportion of $\mathrm{CD} 4^{+} / \mathrm{CD} 25^{+} \mathrm{T}$-cells. A long-term observation is required in order to verify these findings. In addition, the clinical significance of the 4-1BB mAb in managing immune-mediated liver disease remains to be determined.

\section{Acknowledgements}

Medical writing services were provided by Cactus Communications. The authors retained full control of the manuscript content.

\section{References}

1. Kremer AE, Rust C, Eichhorn P, Beuers U and Holdenrieder S: Immune-mediated liver diseases: Programmed cell death ligands and circulating apoptotic markers. Expert Rev Mol Diagn 9: 139-156, 2009.

2. Baier JL and Mattner J: Mechanisms of autoimmune liver disease. Discov Med 18: 255-263, 2014.

3. Lleo A, Invernizzi P, Mackay IR, Prince H, Zhong RQ and Gershwin ME: Etiopathogenesis of primary biliary cirrhosis. World J Gastroenterol 14: 3328-3337, 2008.

4. Levy C and Lindor KD: Primary sclerosing cholangitis: Epidemiology, natural history and prognosis. Semin Liver Dis 26: 22-30, 2006.

5. Krawitt EL: Autoimmune hepatitis. N Engl J Med 354: 54-66, 2006.

6. Hagymási K and Tulassay Z: Review of overlap syndromes in autoimmune liver diseases. Diagnostic and therapeutic difficulties. Orv Hetil 154: 923-929, 2013 (In Hungarian).

7. Krawitt EL: Clinical features and management of autoimmune hepatitis. World J Gastroenterol 14: 3301-3305, 2008.

8. Vinay DS and Kwon BS: Role of 4-1BB in immune responses. Semin Immunol 10: 481-489, 1998.

9. Kwon BS and Weissman SM: cDNA sequences of two inducible T-cell genes. Proc Natl Acad Sci USA 86: 1963-1967, 1989.

10. DeBenedette MA, Wen T, Bachmann MF, Ohashi PS, Barber BH, Stockling KL, Peschon JJ and Watts TH: Analysis of 4-1BB ligand (4-1BBL)-deficient mice and of mice lacking both 4-1BBL and CD28 reveals a role for 4-1BB in skin allograft rejection and in the cytotoxic $\mathrm{T}$ cell response to influenza virus. J Immunol 163: 4833-4841, 1999.

11. Tan JT, Whitmire JK, Ahmed R, Pearson TC and Larsen CP: 4-1BB ligand, a member of the TNF family, is important for the generation of antiviral CD8 T cell responses. J Immunol 163: 4859-4868, 1999.

12. Tan JT, Whitmire JK, Murali-Krishna K, Ahmed R, Altman JD, Mittler RS, Sette A, Pearson TC and Larsen CP: 4-1BB costimulation is required for protective anti-viral immunity after peptide vaccination. J Immunol 164: 2320-2325, 2000. 
13. Kwon BS, Hurtado JC, Lee ZH, Kwack KB, Seo SK, Choi BK, Koller BH, Wolisi G, Broxmeyer HE and Vinay DS: Immune responses in 4-1BB (CD137)-deficient mice. J Immunol 168 : 5483-5490, 2002.

14. Saito K, Mori S, Date F and Ono M: Sjögren's syndrome-like autoimmune sialadenitis in MRL-Faslpr mice is associated with expression of glucocorticoid-induced TNF receptor-related protein (GITR) ligand and 4-1BB ligand. Autoimmunity 46: 231-237, 2013.

15. Martínez Gómez JM, Croxford JL, Yeo KP, Angeli V, Schwarz H and Gasser S: Development of experimental autoimmune encephalomyelitis critically depends on CD137 ligand signaling. J Neurosci 32: 18246-18252, 2012.

16. Jung HW, Choi SW, Choi JI and Kwon BS: Serum concentrations of soluble 4-1BB and 4-1BB ligand correlated with the disease severity in rheumatoid arthritis. Exp Mol Med 36: 13-22, 2004.

17. Liu GZ, Gomes AC, Putheti P, Karrenbauer V, Kostulas K, Press R, Hillert J, Hjelmström P and Gao XG: Increased soluble 4-1BB ligand (4-1BBL) levels in peripheral blood of patients with multiple sclerosis. Scand J Immunol 64: 412-419, 2006.

18. Haga T, Suzuki J, Kosuge H, Ogawa M, Saiki H, Haraguchi G, Maejima Y, Isobe M and Uede T: Attenuation of experimental autoimmune myocarditis by blocking $\mathrm{T}$ cell activation through 4-1BB pathway. J Mol Cell Cardiol 46: 719-727, 2009.
19. Choi BK, Asai T, Vinay DS, Kim YH and Kwon BS: 4-1BB-mediated amelioration of experimental autoimmune uveoretinitis is caused by indoleamine 2,3-dioxygenase-dependent mechanisms. Cytokine 34: 233-242, 2006.

20. Sun Y, Lin X, Chen HM, Wu Q, Subudhi SK, Chen L and Fu YX: Administration of agonistic anti-4-1BB monoclonal antibody leads to the amelioration of experimental autoimmune encephalomyelitis. J Immunol 168: 1457-1465, 2002.

21. Vinay DS, Kim JD and Kwon BS: Amelioration of mercury-induced autoimmunity by $4-1 B B$. J Immunol 7 : 5708-5717, 2006

22. Sun RS, Sui JF, Chen XH, Ran XZ, Yang ZF, Guan WD and Yang T: Detection of CD4+CD25+ FOXP3+ regulatory T cells in peripheral blood of patients with chronic autoimmune urticaria. Australas J Dermatol 52: e15-e18, 2011.

23. Kleczynska W, Jakiela B, Plutecka H, Milewski M, Sanak M and Musial J: Imbalance between Th17 and regulatory T-cells in systemic lupus erythematosus. Folia Histochem Cytobiol 49: 646-653, 2011.

24. Sytwu HK, Lin WD, Roffler SR, Hung JT, Sung HS, Wang CH, Cheng TL, Tsou SC, Hsi SC and Shen KL: Anti-4-1BB-based immunotherapy for autoimmune diabetes: Lessons from a transgenic non-obese diabetic (NOD) model. J Autoimmun 21: $247-254,2003$ 